\title{
Palliative Care in Pediatrics: Perception of the Multiprofessional Team
}

Leonardo Nogueira Melo', Maria José Pessanha Maciel², Luciana Oliveira Simões $^{3}$, Catia Rustichelli Mourão $^{4}$, Emanuel Pereira dos Santos ${ }^{5}$, Edna Corrêa Moreira ${ }^{6}$, Cinthia Torres Leite ${ }^{7 *}$, Mariana de Almeida Pinto Borges $^{8}$, Petra Martins de Mesquita ${ }^{9}$ and Nathalia de Souza Ferreira ${ }^{10}$

${ }^{1}$ MeloNurse at the Federal University of Rio de Janeiro - UFRJ. University Hospital Gafree And Guinle. Specialist by the Multiprofessional Residency Program in Health - UNIRIO.Mastering at PPGSTHE - UNIRIO.Rio de Janeiro - Rio de Janeiro ORCID ID: https://orcid.org/0000-0001-9191-6134

${ }^{2}$ MacielNurse at Veiga de Almeida University, UVA / RJSpecialist in Nursing In Pediatric And Neonatal Icu - Unyleya, Unyleya Faculty Rio de Janeiro - Rio de Janeiro http://orcid.org/0000-0003-1092-0911

${ }^{3}$ Specialist nurse in pediatric, work institution Hospital University Gafree E Guinle

${ }^{4}$ Nursing Technician to pediatric Hospital University Gafree and Guinle. Titulation: Work Nurse

${ }^{5}$ Master Nurse, Working institution Hospital Universitário Gafree e Guinle ORCID:https://orcid.org/0000-0001-9191-6134

${ }^{6}$ Social Assistent of Paliative care of HUGG Specialist in Law and Health - DIHS / ENSP / FIOCRUZSpecialization in Palliative Care - Albert Einstein InstituteMaster in Bioethics - IMS / UERJ / PPGBIOSRio de Janeiro - Rio de Janeiro

${ }^{7}$ Physiotherapist, specialist critical care neonatal and pediatric ICU, master in women's and children's health, working institution Hospital Universitário Gafree e Guinle in uniti critical care neonatology ORCID: http://orcid.org/0000-0001-9049-9367

${ }^{8}$ Pediatrician / Neonatologist at the Federal University of the State of Riode Janeiro - UNIRIO. PhD student in Science at PPGENFBIO / UNIRIO. Rio de Janeiro - Rio de Janeiro

${ }^{9}$ Physiotherapist to critical care Hospital University Gafree and Guinle. Graduation pos in trauma orthopedics by UNAMA and specialist acunpunture

${ }^{10}$ physiotherapist, Working institution Hospital University Gaffrée e Guinle, residency in physiotherapy

\section{"Correspondence author}

\section{Dr. Cinthia Torres Leite}

Physiotherapist

Specialist critical care neonatal and pediatric ICU

Master in women's and children's health

Working institution Hospital Universitário Gafree e Guinle in uniti critical care neonatology

ORCID: http://orcid.org/0000-0001-9049-9367

Brazil

Submitted : 15 April 2020 ; Published : 25 May 2020

\begin{abstract}
Introduction: Palliative care with the Cicely Saunders, in the 20th century and consists of the care and assistance to the patient and their families, ensuring better quality of life, aiming at controlling pain and suffering, with attention to physical aspects, spiritual, social and psychic.

Objectives: To approach the respiratory and motor care of a pediatric patient in palliative care by nursing and physiotherapy, restricted to the bed, with non-progressive Hypoxic-Ischemic Encephalopathy, with metabolic syndrome under investigation, chronic pulmonary disease dependent on oxygen, alternating macronebulization and ventilatory prosthesis (PSV) for nocturnal breathing comfort.
\end{abstract}


Methodology: This is an experience report lived by residents in a public university hospital in Rio de Janeiro, during the month of June 2018 in the pediatric ward. Through multidisciplinary action, interventions were carried out to improve the patient's condition and minimize pain aspects through the care of the patient's respiratory and motor functions and maternal guidance.

Results and Discussion: Bearing in mind that palliative care focuses on minimizing pain and suffering, the actions presented above are in line with most of the published studies relating palliative care and improving quality of life with reducing the suffering of child and family members, guided by the bioethical principles of beneficence and non-maleficence.

Conclusion: Through the applied procedures, greater independence of the ventilatory prosthesis was found, enabling the strengthening of the family bond, concomitant to the learning of the professionals involved related to palliative care in pediatric patients.

\section{Introduction}

Palliative care started with the pioneer Cicely Saunders, in the 20th century and consists of care and assistance to the patient and their families, ensuring better quality of life, aiming at controlling pain and suffering, with attention to physical, spiritual and social aspects and psychic [1].

Since the twentieth century, important issues have been discussed about palliative care in all areas, from adult / elderly clinics, cancer patients, to pediatric patients in general, through the hospice movement, which sought to fill gaps in relation to quality of life. Patients and their families, who until now had made incipient care.

According to the Worldwide Palliative Care Alliance, although more than one hundred million people benefit from palliative care annually (including family members and caregivers), less than $8 \%$ who need this type of assistance have their in fact guaranteed access [2].

Even though it is a large population worldwide, few of them have access to care in a dignified manner, because in addition to the annual number being huge, with about 100 million individuals, it is necessary that patients have access to specific medications for pain control, measures that allow a death without discomfort and the implementation of government policies in palliative care.

The approach focused on the human being in its entirety and the need to intervene in symptoms of a physical, social, emotional and spiritual nature transform the practice of palliative care into necessarily a team work, of an interprofessional character, which includes doctors, nurses and nursing technicians, social workers, psychologists, pharmacists, physiotherapists, occupational therapists, nutritionists, spiritual assistants of an ecumenical character or of the religion chosen by the patient $[3]$.

The specificity in pediatric care from the perspective of palliation, requires that professionals involved in care constantly assess the physical, psychological and social suffering of both the child and those responsible for it, through broad, interdisciplinary approaches, with the use of possible tools, making active care [4].
Child palliation differs from palliative care in adults due to some characteristics, such as the rarity of some diagnoses that occur only during childhood, the conflicting situation experienced by parents due to the obscurity of pain and anxiety involving the probable loss, at the same time as these, as caregivers, commit all their affection and genetic counseling, where it is necessary to clarify the etiological mechanisms of genetic diseases, and the definitions of the risks of occurrence / recurrence, which are of great importance for families with these types of diseases [4]

Difference between pediatric palliative care and palliative care in adults

\begin{tabular}{|l|l|}
\hline a & The prognosis, life expectancy and functional results
\end{tabular} are indisputable in pediatrics.

b There is a greater need to integrate palliative care with intensive treatments to modify the disease or maintain life due to the unclear prognosis in children.

c Care generally requires a double focus on growth / development and the potential for death

d It has a greater emotional burden for family members and doctors, because serious illnesses and treatment for life are generally not considered normal conditions for children.

e Patients experience continuous changes in development: physical, hormonal, cognitive and emotional.

f Patients change information needs, recreational and educational needs and ways of dealing with stress.

g Pediatric palliative care may also involve a therapist, a child therapist and / or a child behavior specialist.

h Patients may have congenital anomalies of an uncertain type or rare genetic compromises.

i Some genetic conditions can affect several children in a family and create a sense of guilt in the parents.

$\mathrm{j}$ Specialization is required to discern the child's emotional and cognitive development and to properly communicate both topics. Provide the most appropriate amount and type of information about the disease and extract your child's care preferences.

$\mathrm{k}$ Care decision-making authority remains with parents, not with children. Adult patients can make their own decisions. 
Source: Adapted from WORLD HEALTH ORGANIZATION (2018), HAUER (2019).

The multiprofessional team is in direct contact with the patient and his suffering during the entire period of his hospitalization. This contact causes suffering to professionals, especially when he is a pediatric patient in palliative care.

In palliative care, regardless of the assisted public, the multiprofessional team is constantly concerned with Bioethics, promoting good for the patient that is, exercising the principle of beneficence. It is worth mentioning that the aforementioned principle differs [but does not intend] essentially from the principle of non-maleficence, in the sense that it requires taking positive attitudes towards others, and not only failing to perform acts that harm or cause harm to people. It is the "moral obligation to act for the benefit of others [9]".

\section{Objective}

The objective of this study is to address, through the joint action of nursing and physiotherapy, the respiratory and motor care of a pediatric patient in palliative care, restricted to the bed, with non-progressive Hypoxic-Ischemic Encephalopathy and genetic syndrome by mutation of the KCNQ2 gene, chronic lung disease dependent on oxygen therapy, alternating between macro nebulization through tracheostomy and ventilatory prosthesis in support pressure ventilation mode, for nocturnal breathing comfort.

Although the literature presents a small amount of studies involving the management of a patient with a mutation in the KCNQ2 gene, which encodes voltage-dependent potassium ion channel subunits (5), the authors believe that it is the responsibility of the professionals involved to appropriate even more the technologies of care, making it necessary to carry out further investigations on the exposed theme.

The relevance of the study is emphasized through the importance of joint action in the implementation of the patient's quality of life and therapeutic management, as the findings may favor the planning of strategies aimed at safe care and the development of best health practices based on evidence.

\section{Methodology}

This is an experience report lived by nursing and physical therapy residents and their respective preceptors, in a public university hospital in Rio de Janeiro, during their professional performance in June 2018, in the pediatric ward.

Through multiprofessional action, interventions were planned and carried out to improve the condition and minimize pain aspects through care with the respiratory, motor and maternal guidance, generating an improvement in the quality of life for the hospitalized patient.

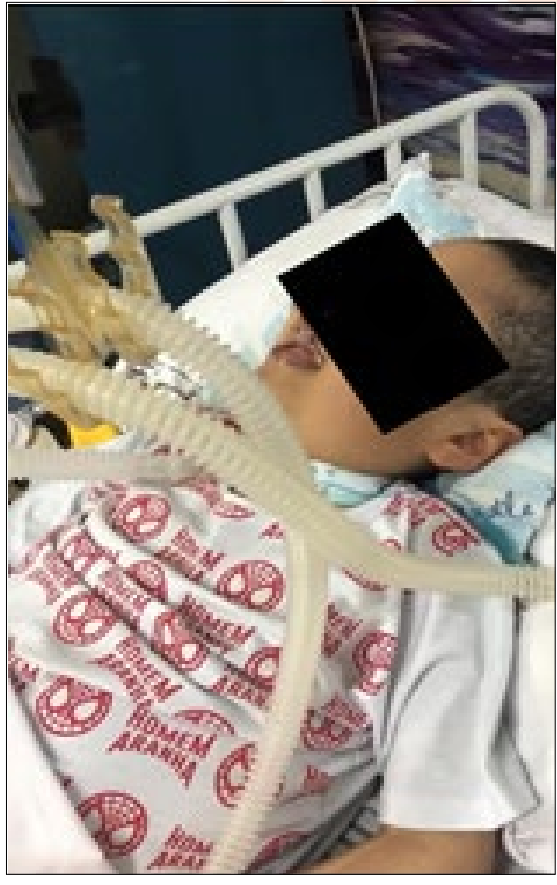

Source: Authors of the article

\section{Results and Discussion}

In our case report, seizures occurred within hours of the patient's birth. Athermo was born, at 40 gestational weeks, due to cesarean delivery due to fetal distress, apgar $8 / 9$, birth weight $3,530 \mathrm{~g}$, without complications. After the first hours of life, he developed seizures that were difficult to control, and generalized hypotonia, and then started to use anticonvulsants. Gastrostomy was performed for food and medication. $\mathrm{He}$ evolved in the first years of life with respiratory failure, requiring assistance with oxygen therapy and invasive mechanical ventilation later, and the tracheostomy was performed due to difficult extubation. In genetic research, genetic syndrome by mutation of the KCNQ2O gene was found.

Currently an 8-year-old patient, he continues to use anticonvulsants and the aid of invasive mechanical ventilation coupled to a 5.5 tracheostomy with cuff. Epilepsies form a group of chronic neurological syndromes, resulting from changes in brain functions, associated or not with other pathological conditions. Epileptic syndromes are divided into symptomatic, cryptogenic and idiopathic. While in symptomatic epilepsy, epileptic seizures represent a symptom of structural damage to the nervous system, cryptogenic seizures have a presumed organic basis, but without a defined etiology. Idiopathic epilepsies are those without a probable lesion substrate, probably related to genetic predisposition. Idiopathic means that epilepsy itself is the disease and not a symptom of some other condition [5].

Children with brain injuries need advanced life support for their treatment, depending on the location of the injury, neural control of breathing can be prevented, and the use of mechanical ventilation (MV) is necessary to ensure comfort, 
quality and many times greater Living conditions.

Mechanical ventilation in pediatrics is based, to a large extent, on the experience of intensivists accumulated over the years of professional practice, with acid-base imbalances being managed and parameters regulated in order to guarantee improvement in gas exchange, not occurrence of injury related to mechanical ventilation and strategies for weaning and discontinuing ventilatory support [6].

The physiotherapist in conjunction with the interdisciplinary team is important in the management of $\mathrm{MV}$ and in caring for the patient's functionality with the aim of making him the most participant in the environment, ensuring greater interaction with the environment and with family members, in addition to greater independence of the ventilatory prosthesis.

In the physiotherapeutic care adopted, daily bronchial towel techniques and weaning from the ventilatory prosthesis in macronebulization for two hours (when possible, aiming at endurance and diaphragmatic training) were used prior to essential nursing care, thus facilitating patient hygiene and movement in bed. , offering a better quality of life for him as well as security in the essential procedures and also providing greater ease in transferring the patient from the bed to the lap of the mother, thus corroborating with the objective of humanization in health.

The response to the procedure proved to be good, mainly providing moments of humanized care with the transfer of the patient from the bed to the mother's lap regardless of MV, using oxygen therapy by macronebulization (oxygen ranging from 3 to 5 liters) maintaining good vital signs and good behavioral status, as well as the mother's emotional well-being was also observed.

It is important in treatment to focus, whenever possible, on continuous efforts to control the underlying disease, with an interdisciplinary team helping the child, family and caregivers and also helping each other in the care process. Children and their families must have access to interdisciplinary care aimed at promoting ideal physical, psychological and spiritual wellbeing. Persistent myths and misconceptions lead to inadequate symptom control in children with life-limiting illnesses $[2,7,8]$.

Palliative care includes a holistic approach focused on the patient and his surroundings, as well as on the development and reliance on robust evidence to make rational therapeutic decisions. A constant emphasis on combining these two factors to balance the burden and benefits, ensuring that the individual's best interests remain preserved. These become particularly important in palliative care, when the goal of treatment becomes the maintenance of quality of life $[2,7,8]$.

Bearing in mind that palliative care focuses on minimizing pain and suffering, the actions presented above are in line with most of the published works relating palliative care and improving the quality of life with reducing the suffering of children and family members, guided by the bioethical principles of beneficence and non-maleficence.

\section{Conclusion}

Through the applied procedures, greater independence of the ventilatory prosthesis was found, enabling the strengthening of the family bond, concomitant to the learning of the professionals involved related to palliative care in pediatric patients.

Descriptors: Palliative Care, Pediatrics, Physiotherapy, Chronic Disease, Pediatric Nursing

\section{Reference}

1. Gomes ALZ, Othero (2016) MB Palliative care. Estud. av., Sao Paulo 30(88): 155-166. Available $\mathrm{K} 40142016000300155 \& \operatorname{lng}=$ en\&nrm $=$ iso $>$. $\quad$ access on 10 Oct. 2019. http://dx.doi.org/10.1590/ s010340142016.30880011.

2. Worldwide Palliative Care Alliance (2014) Global Atlas of Palliative Care at the End of Life. WHO. England. 2014. Disponível http://www.who.int/nmh/Global_Atlas_ of_Palliative_Care.pdf.

3. Maciel MGS (2008) Definitions and principles. In: Palliative Care. Sao Paulo: Cremesp p.18-21.

4. Iglesias SBO, Zollner ACR, Constantino CF Pediatric Palliative Care. Rev. Brazilian Society of Pediatrics 6 (suppl 1): 46-54.

5. Cendes IL, Ribeiro PAO Genetic aspects of epilepsy: a current view. Rev. Med. Clin. Counts 24(6): 903-908.

6. Kneyber MCJ, Luca D, Calderini E, Jarreau PH, Javouhey E, et al. (2017) Recommendations for mechanical ventilation of critically ill children from the Paediatric Mechanical Ventilation Consensus Conference (PEMVECC). Intensive Care Med 43: 1764-1780. Disponível em: https://www.ncbi.nlm.nih.gov/pubmed/28936698

7. Mcnamara-Godger K, Feudtner C (2012) History and Epidemiology. In: GOLDMAN, A.; HAIN, R.; LIBEN, S. Oxford Textbook of Palliative Care for Children. Oxford University Press: New York 2012.

8. Friedrichsdorf SJ, Bruera E (2018) Delivering Pediatric Palliative Care: From Denial, Palliphobia, Pallilalia to Palliactive. Children (Basel, Switzerland) 5(9): 120.

9. Beauchamp TL, Childres JF (2011) Principles of Biomedical Ethics. Trad. Luciana Pudenzi. Loyola Editions, São Paulo, 2nd ed. p. 282.
Copyright: (C2020 Cinthia Torres Leite. This is an open-access article distributed under the terms of the Creative Commons Attribution License, which permits unrestricted use, distribution, and reproduction in any medium, provided the original author and source are credited. 